\title{
Integrated Fuzzy System and Multi-Expression Programming Techniques for Supplier Selection
}

\author{
Marija PAUNOVIĆ, Nebojša RALEVIĆ, Olivera MILUTINOVIĆ, Željko VOJINOVIĆ, Biljana MLADENOVIĆ-VOJINOVIĆ
}

\begin{abstract}
Supplier selection problem is a multi-objective problem in which different criteria should be taken into consideration. This article presents a new approach to supplier pre-qualification, supplier selection and evaluation. In the first stage of the model, multi-expression programming (MEP) techniques are used for a supplier prequalification. Techniques implemented in MEP allow construction of experiential models using the knowledge contained in the experimental information. Evaluation of the qualified suppliers is done in the second stage using fuzzy logic and Fuzzy Inference System (FIS). In this way, it is possible to retain expert knowledge of the subject phenomenon in a model with the possibility of selecting different operators which lead to the possibility of the faster selection of parameters and making more reliable decisions. Numerical examples are presented to demonstrate the proposed approach
\end{abstract}

Keywords: fuzzy system; multi-expression programming; supplier evaluation

\section{INTRODUCTION}

The supplier selection process has various steps such as setting up the problem, formulating criteria that are important in deciding and prequalifying potential suppliers, evaluating suppliers, and ultimately choosing a quality choice. Managing a large number of suppliers is a complex and demanding process. Prequalification, or reduction of the number of potential suppliers to a set with a smaller number of suppliers and eligible suppliers, is a sorting process. The scope and diversity of suppliers make the process stiff [1-7]. Special attention must be focused on the quality of the steps that we have included in the process and that leads to quality of the final choice.

The process of selecting suppliers is a multiobjective problem in which different criteria should be taken into consideration. Various mathematical techniques have been used by the researchers for selection and evaluation of suppliers. In the evaluation and selection of suppliers, the decision maker must take into account qualitative and quantitative data. Authors are trying to resolve the complexity of supplier selection problem by applying hybrid models. Imprecise information that is inherent in real life problems cannot be effectively addressed by classical MCDM techniques. Fuzzy hybrid approaches can be used to solve very complex real-world decision-making problems such as a supplier assessment, ranking and supplier selection. On the other hand, the Artificial Intelligence methods successfully bring better results when dealing with complex, multicriterial and uncertain tasks than a traditional method. Some advantages of these techniques are: automaticly data transforming, flexibility related to the specificity of the problem, ability to derive, at the same time, various subtasks convoluted in the categorization etc.

In this paper a new model for supplier prequalification, supplier selection and evaluation has been presented. In the first stage of the model, multi-expression programming (MEP) techniques are used for supplier prequalification. MEP techniques are substantially helpful to determine empirical models and to indicate behavior by directly extracting experimental information. Unlike various soft computing techniques, MEP is providing racionally abridged indicators (ie. equations). Evaluation of the qualified suppliers is done in the second stage using fuzzy logic and Fuzzy Inference System (FIS).

The system based on fuzzy rules that is suggested leads to the modeling of human interpretation. This method assists in the process of decision-making to extract and maintain experience in the model, with the ability to select different operators. In this way, it is possible to retain expert judgment of the subject phenomenon in a model which leads to the faster selection of parameters and making more reliable decisions, and that is one of the main shortcomings of the MCDM fuzzy methods.

The other parts of the paper are organised as follows: an overview of the recent relevant researches has been presented in section 2. Problem formulation is presented in section 3. Section 4 presents the algorithm MEP. Proposed model and its structure as implemented in this research is given in section 5. Computational analysis of the proposed approach is shown in section 6. Finally, conclusion marks are presented in section 7 .

\section{RELATED RESEARCH}

The scope and diversification of suppliers make the complex system and can lead to wrong processes. Decision makers are dealing with a wide diversity of directions which conduct to various judgment. In the review paper of Abdolshah [8] were presented 23 criteria for supplier evaluation and supplier selection. Mathematical methods are employed to perform the complex structure of supplier selection and have been applied extensively to model the problems of selection and allocation issues.

Soft computing techniques are a group of unique methodologies, often complement to each other, and prepare extensible knowledge handling efficiency in solving real-life issues. Summarized conclusions of the related reseraches in soft computing applications are given in Ko et al. [9]. They emphasize importance of those tehniques in analyzing informations and accomplishing decision in complex situations.

Fuzzy multiple criteria decision-making models and applications showed that the technique of Fuzzy Analytic Hierarchy process (FAHP) was the most used one among 
MCDA techniques that employed fuzzy decision making tools and approaches [10]. Mathematical model for supplier selection in the purchasing stage was introduced by Zhi Li [11]. Their SSOA model comprises two processes, fuzzy extent Analytic Hierarchy process (FEAHP) with multi-objective dynamic linear programming technique.

Mohsen Jafari Ashlaghi [12] presented hybrid model for green supplier selection which integrated DEMATELFuzzy ANP and managing mutuality between different criteria. Model uses the opinion of the decision makers efficiently to gain the weight of criteria and to deal with restrictions. A two phase, multicriteria method for selecting aluminum suppliers in the vehicle's exhaust system has been introduced by Bronja and Bronja [13] Weighted element estimation was standardized with the mean square, and distance from the ideal solution was carried out with a modefied TOPSIS technique.

$\mathrm{Wu}$ [14] introduced a hybrid model that first uses DEA and clusters classification on the efficacy results, and then uses performance data for training models and neural network models. The trained tree model was applied to new suppliers and accomplishes acceptable classification and forecasting accuracy rate. Vandans et al. [15], developed the AI model to predict suppliers' ranking in the cosmetics corporations.

MEP techniques application in civil engineering domain is introduced in [16]. Alireza Fallahpour [17] proposes an integrated system for a supplier selection based on an analytical hierarchy process combined with MEP. Proposed system has limitation that arises when dealing with a higher number of elements and subelements which increases the complexity of the computation.

The Fuzzy Inference System has been applied in many areas, in various engineering problems as well as in supply management. Papers of Chen et al. [18] and Chen [19] proposed fuzzy techniques as a powerful application for the analysis of structural problems under the outer actions.

\section{PROBLEM FORMULATION}

According to the extensive literature on supplier selection, the following characteristics should be taken into account when solving the issues of supplier selection [20]. First, the procedure of selecting suppliers requires consideration of several often contradictory criteria. Second, many experts are often involved in the detemination. Third, uncertainty is often determined in real life. It is imperative that in such processes we know the weight and classification of elements, which in practice cannot always be represented by numerical values. Suppliers evaluation is a mechanism that leads companies to choose prefered suppliers. In this process, companies engage expert teams for evaluating various elements and sub-elements, and to do a comprehensive assesment. Consequently, the most relevant approaches for solving this problem are multi-objective. It is important to select a flexible method with an objective evaluation which ensures an intelligent approach.

\section{MULTI-EXPRESSION PROGRAMMING (MEP)}

Multi-expression programming (MEP) is a variant of GP. First step starts with GA and selection of the random population. When choosing an individual, the following conditions must be respected [21]:

1) First gene of the chromosome must have a terminal randomly chosen from terminals data.

2) Other genes are determined by selection on random base a terminal from the set of terminals or a function from the set of functions. Genes that encode function, indexes must be generated to refer to function variables. Marks must indicate toward genes with a lower index than the current gene.

Prefered expression is chosen after checking the fitness of all expressions in MEP chromosome described with [23]:

$$
f=\min _{i=l, g}\left\{\sum_{j=1}^{n}\left|E(k)-O_{k}^{i}\right|\right\}
$$

where $n$ indicate the number of fitness cases; $E(k)$ expected value for case $k ; O_{k}^{i}$ is the rate that comes for the $k^{\text {th }}$ case by the $i^{\text {th }}$ expression encoded in the current chromosome; $g$ is the number of genes.

Performance evaluation obtained from the models, the correlation coefficient $(R)$, root mean squared error (RMSError) and mean percent error (MAError) were applied:

$$
\begin{gathered}
R=\frac{\sum_{i=1}^{n}\left(a_{i}-\bar{a}_{i}\right)\left(y_{i}-\bar{y}_{i}\right)}{\sqrt{\sum_{i=1}^{n}\left(a_{i}-\bar{a}_{i}\right)^{2} \sum_{i=1}^{n}\left(y_{i}-\bar{y}_{i}\right)^{2}}} \\
\text { RMSErrors }=\sqrt{\frac{\sum_{i=1}^{n}\left(a_{i}-y_{i}\right)^{2}}{n}} \\
\text { MAErrors }=\frac{1}{n} \sum_{i=1}^{n}\left|a_{i}-y_{i}\right|
\end{gathered}
$$

where $a_{i}$ is the actual (observed) value; $y_{i}$ is predicted output values; $\bar{a}_{i}$ the average of the observed outputs; $\bar{y}_{i}$ average of the predicted outputs.

The MEP present the genes using substrings of variable length and their number in chromosome is constant. In the decoding process MEP achieves that no cycle arises (phenotypically transcribed). An important feature implemented in the MEP is to set the first chromosome symbol as a terminal symbol. This ensures synthetically correct individuals. The advantage of the MEP in relation to traditional methods results in modeling automated behavior without necessity for predefining the model formation.

Comprehensive details about MEP can be found in work of Alavi and Gandomi [22].

In our approach each element presents a supplier and fitness function measures preferences of each supplier. The objective of the evolutionary procedure is to do a suppliers pre-qualification. 


\section{PROPOSED APPROACH}

This paper proposes an inovative multi-objective evolutionary algorithm for solving supplier selection task and supplier evaluation using fuzzy techniques. The first phase refers to establishment of input parameters and a hierarchical structure of the problem. Input values are expert estimates of relationship between values.

Table 1 Linguistic variables for criteria weights

\begin{tabular}{|l|c|}
\hline \multicolumn{1}{|c|}{ Linguistic scale } & Fuzzy scale \\
\hline Just equal & $(1,1,1)$ \\
Equally important & $(1 / 2,1,3 / 2)$ \\
Weakly important & $(1,3 / 2,2)$ \\
\hline Strongly important & $(3 / 2,2,5 / 2)$ \\
Very strongly important & $(2,5 / 2,3)$ \\
Absolutely important & $(5 / 2,3,7 / 2)$ \\
\hline
\end{tabular}

MEP accepts the data set related to suppliers. The available data sets are at random basis assigned into learning, validation and testing subgroups and with that procedure over fitting is evaded. The learning information is for genetic evolution. The informations from the validation part are used to determine the possibility of generalizing the model on the data on which they were not trained. In that way, learning and validation sets were involved in the modelling process and were categorized into one group attributed to as training data. The model with the best achievement of both learning and validation information is definitely chosen as the result. The testing data sets are used as criterion of the optimal models gained from MEP on data without role in constructing the models. With a goal to grade the performance of suppliers, the model is using the correlation coefficient, root mean squared error and mean percent error.

The selection of qualified suppliers, i.e. a conclusion on suppliers with the best performances is done by observing higher value of $R$ with low RMSError and MAError.

Preparation of data for FIS is the next phase of the system. Each element can be described by fuzzy sets as low, medium and high, and they are presented as triangular fuzzy numbers. Values $x_{1}, x_{2}, x_{3}, x_{4}, x_{5}$ and $x_{6}$ for left and right border, and the value with the highest level of membership of fuzzy numbers are different for each element.

The output value of the fuzzy system is evaluation in specific process $(\mathrm{EV})$ and membership functions, defined in the range $[0,100]$, of fuzzy sets

$\mu_{Y_{\mathrm{VL}}}(y)=[0,0,20]-$ Very low,
$\mu_{Y_{\mathrm{L}}}(y)=[5,25,45]-$ Low,

$\mu_{Y_{M}}(y)=[30,50,70]-$ Medium,

$\mu_{Y_{\mathrm{H}}}(y)=[55,75,95]-$ High,

$\mu_{Y_{\mathrm{VH}}}(y)=[80,100,100]$ - Very high.

Based on defined interval of value $I_{i}$ of input variables, left and right boundary can be set, and the value with the highest level of membership of fuzzy numbers $X_{\mathrm{L}}, X_{\mathrm{M}}$ and $X_{\mathrm{H}}$, for each element: $x_{i 1}=0.1 I_{i}, x_{i 2}=0.3 I_{i}, x_{i 3}=0.5 I_{i}, x_{i 4}=0.7 \mathrm{I}_{\mathrm{i}}$, $x_{i 5}=0.9 I_{i}$, and $x_{i 6}=I_{i}[23]$. The output of the fuzzy system is in the interval $(0,100)$. Those values represent the value of total evaluation.

In the process of the approximate reasoning for each triggered rule, the inference machine is applying an indication relation between the fuzzy number as a result of the logic operations and the consequent.

Implication operator, employed in this work is the MIN, defined as

$$
\mu(x, y)=\operatorname{MIN}\left\{\mu_{\mathrm{A}}(x), \mu_{\mathrm{B}}(x)\right\}
$$

In the last faze the process is implemented in the model and problem was solved by using MATLAB ${ }$ software.

\section{PROCEDURE AND RESULTS OF A MODEL}

The manufacture packaging factory uses numerous relationships to customers, suppliers, and other partners. The factory uses a relatively rational, in general qualitative procedures, to assess a supplier. The methodology follows upsettled phases to analyze a supplier and requires a series of standard and structured tools and procedures to assemble and analyze information together with generating reports. The expert team of engineers is associated with topic technology on extensive and operable principles and to their best knowledge and experience evaluated suppliers.

Five criteria were observed (Tab. 2) about supplier characteristics (quality, delivery performance, technical capability, price/cost, and flexibility) and applied to the manufacture packaging factory. Data set contains an expert opinion according to pre-defined criteria about 35 suppliers shown in Tab. 3.

To reach a steady data division, several solutions of the training and testing sets are treated. Data sets were randomly splited into learning, validation and testing subgroups. In order to get optimal models, main arithmetic operators and mathematical functions are handled.

Table 2 Supplier selection and evaluation criteria

\begin{tabular}{|l|l|}
\hline Cost & Product price, logistics cost, payment terms [24, 25] \\
\hline Quality & ISO quality system installed, product performance, warranties and claim policies, and repair rate [26] \\
\hline Delivery & Lead time, on-time delivery, safety and security of components [27] \\
\hline Technology & Communication systems, research development, innovation, and production facilities and capacity [28] \\
\hline Flexibility & Product volume changes, appling adjustable machines, parameters required to implement new products etc. [29] \\
\hline
\end{tabular}

All combinations of the parameters are tested and ten replications are performed for each combination. Parameters of a model are shown in Tab. 4.

The R, RMSError and MAError values of the model on the training data are equal to $0,953,0,012$ and 0,007 , respectively. In the testing stage, $R, R M S E r r o r$ and MAError are 0,932,0,006, and 0,004, respectively. Smith [30] proposed the following criteria for performance evaluation: for $|R|>0.8$, a strong correlation exists, for 
$0.2<|R|<0,8$ a correlation exists and for $|R|<0.2$, a weak correlation exist.

A conclusion on suppliers with the best performances is done by observing higher $\mathrm{R}$ values with lower RMSError and MAError. According to the individual fitness and validation process, and for illustration of the model, 2 suppliers were selected, Supp 2 and Supp 3.
Fuzzy system has five inputs and approximate reasoning algorithm includes 243 fuzzy rules which represent a set of variations with repetition of set (quality, delivery performance, technical capability, cost, flexibility, evaluation) and levels (very low, low, medium, high and very high).

Table 3 Supplier assessment and system output

\begin{tabular}{|c|c|c|c|c|c|c|}
\hline & Cost $(C)$ & Quality $(Q)$ & Technology $(T)$ & Delivery $(D)$ & Flexibility $(F)$ & Output \\
\hline Supp 1 & 0,2470 & 0,3423 & 0,2962 & 0,0880 & 0,0264 & 0.53 \\
\hline Supp 2 & 0,2688 & 0,4514 & 0,1950 & 0,0155 & 0,0693 & 0.65 \\
\hline Supp 3 & 0,2630 & 0,4298 & 0,2410 & 0,0316 & 0,0345 & 0,66 \\
\hline Supp 4 & 0,1223 & 0,2515 & 0,3099 & 0,1195 & 0,1968 & 0,37 \\
\hline Supp 5 & 0,3600 & 0,3812 & 0,1046 & 0,0165 & 0,1376 & 0,42 \\
\hline Supp 6 & 0,1210 & 0,2560 & 0,3173 & 0,1267 & 0,1789 & 0,39 \\
\hline Supp 7 & 0,3266 & 0,2846 & 0,2293 & 0,1120 & 0,0474 & 0.36 \\
\hline Supp 8 & 0,1223 & 0,2515 & 0,3099 & 0,1195 & 0,1968 & 0,37 \\
\hline Supp 9 & 0,1235 & 0,2541 & 0,3130 & 0,1017 & 0,2077 & 0,38 \\
\hline Supp 10 & 0,0732 & 0,2488 & 0,3715 & 0,1848 & 0,1217 & 0,41 \\
\hline Supp 11 & 0,1112 & 0,2447 & 0,3059 & 0,1947 & 0,1435 & 0,39 \\
\hline Supp 12 & 0,1186 & 0,2749 & 0,3091 & 0,2009 & 0,0964 & 0,32 \\
\hline Supp 13 & 0,1906 & 0,2662 & 0,3048 & 0,1917 & 0,0467 & 0,33 \\
\hline Supp 14 & 0,1988 & 0,2565 & 0,2267 & 0,2312 & 0,0868 & 0,33 \\
\hline Supp 15 & 0,1986 & 0,2580 & 0,2430 & 0,2168 & 0,0837 & 0,34 \\
\hline Supp 16 & 0,0691 & 0,2599 & 0,2447 & 0,2183 & 0,2079 & 0,35 \\
\hline Supp 17 & 0,0140 & 0,2702 & 0,1968 & 0,3176 & 0,2013 & 0,20 \\
\hline Supp 18 & 0,0052 & 0,2614 & 0,2549 & 0,3091 & 0,1695 & 0,19 \\
\hline Supp 19 & 0,1033 & 0,2628 & 0,2566 & 0,3076 & 0,0697 & 0,21 \\
\hline Supp 20 & 0,1109 & 0,2687 & 0,2002 & 0,3127 & 0,1074 & 0,12 \\
\hline Supp 21 & 0,0140 & 0,2702 & 0,1968 & 0,3176 & 0,2013 & 0,31 \\
\hline Supp 22 & 0,1876 & 0,2675 & 0,1949 & 0,3145 & 0,0354 & 0,29 \\
\hline Supp 23 & 0,2047 & 0,2310 & 0,2015 & 0,3215 & 0,0412 & 0,26 \\
\hline Supp 24 & 0,1371 & 0,2616 & 0,1866 & 0,3292 & 0,0855 & 0,29 \\
\hline Supp 25 & 0,2061 & 0,2950 & 0,2603 & 0,2271 & 0,0115 & 0,40 \\
\hline Supp 26 & 0,2081 & 0,2911 & 0,2586 & 0,1525 & 0,0898 & 0,39 \\
\hline Supp 27 & 0,1483 & 0,2896 & 0,2555 & 0,2283 & 0,0784 & 0,46 \\
\hline Supp 28 & 0,1282 & 0,2969 & 0,3172 & 0,2070 & 0,0507 & 0,37 \\
\hline Supp 29 & 0,0313 & 0,2645 & 0,2823 & 0,2165 & 0,2055 & 0,27 \\
\hline Supp 30 & 0,0576 & 0,2220 & 0,2387 & 0,2086 & 0,2732 & 0,26 \\
\hline Supp 31 & 0,1340 & 0,2177 & 0,2304 & 0,2055 & 0,2124 & 0,18 \\
\hline Supp 32 & 0,1198 & 0,2128 & 0,2282 & 0,1911 & 0,2481 & 0,15 \\
\hline Supp 33 & 0,0961 & 0,1955 & 0,2281 & 0,1807 & 0,2996 & 0,13 \\
\hline Supp 34 & 0,1310 & 0,3033 & 0,3240 & 0,2318 & 0,0099 & 0,48 \\
\hline Supp 35 & 0,0581 & 0,3726 & 0,2385 & 0,2291 & 0,1017 & 0,54 \\
\hline
\end{tabular}

Table 4 Parameter settings

\begin{tabular}{|l|c|}
\hline \multicolumn{1}{|c|}{ Parameter } & Parameter setting \\
\hline Generation number & 500 \\
\hline Population Size & 500,2000 \\
\hline Code length & 50,100 \\
\hline Tournament Size & 4 \\
\hline High level crossover rate & 0,50 \\
\hline Low level crossover rate & 0,85 \\
\hline Probability of mutation & 0,01 \\
\hline
\end{tabular}

Table 5 Fuzzy system output

\begin{tabular}{|c|c|c|c|c|c|}
\hline Variable & $C$ & $Q$ & $T$ & $D$ & $F$ \\
\hline Supp2 & 0,2713 & 0,4632 & 0,1835 & 0,0154 & 0,0666 \\
\hline Supp3 & 0,2727 & 0,4203 & 0,2397 & 0,0334 & 0,0339 \\
\hline
\end{tabular}

Simulation process is implemented in model and problem was solved by using MATLAB $\AA$ software. Table 5 summarized the results obtained by model for each supplier in respect of five major aspects.

The highest value in supplier evaluation process contains quality and cost for both suppliers. For the Supp2 quality is $46,32 \%$ and for Supp3 is $42,03 \%$. Cost is on the similar level for both suppliers of $27,13 \%$, i.e. $27,27 \%$. Technology criterion takes the third place for selected suppliers with 18,35\%, for Supp2 and 23,97\% for Supp3. Delivery and flexibility criteria are on a low level for both selected suppliers. According to its preferences, the company further recommends a supplier.

Consistency of the obtained results can be noticed (Tab. 3 and Tab 5.). Problem of inconsistency in output data of FAHP [31] (Chang's method) is solved using fuzzy logic, as it enables a relatively simple correction of model parameters and ensures more precise numerical value.

\section{CONCLUSION}

This paper introduced an integrated approach based on expert opinion, multi-expression programming and fuzzy logic for supplier pre-qualification, supplier selection and evaluation. In the first stage of the system, multiexpression programming techniques are used for supplier pre-qualification. MEP techniques are substantially effective in determing observational models for explaining the behaviour by straight derivating the knowledge incorporated in the experimental information. MEP techniques provide reasonably simplified prediction 
equations. It enables selection of data sub-set, creating new attribute by using various mathematical operators through the original or find out the relevance and the significance of the attributes. Evaluation of the qualified suppliers is done in the second stage using fuzzy logic and Fuzzy Inference System (FIS). The idea to minimize the subjectivity degree of decision makers is realized by using fuzzy logic model. Experts assess the value for each of total elements, while assessment of the total evaluation is realized by using a Fuzzy Inference System.

Five major aspects: quality, delivery performance, technical capability, cost and flexibility, were applied to evaluate suppliers. The other demanding elements can be implemented in this system. Proposed model is flexible. Estimation of individual elements can be applied using different scales, whose value ranges can be adjusted to the practice. The method increases the accuracy of the assessment of each particular evaluation that belongs to a particular category class. The proposed approach can be further improved by integration of various priority rules that can accelerate the evaluation process.

\section{Acknowledgement}

The second author acknowledges the financial support of the Ministry of Education, Science and Technological Development of the Republic of Serbia, in the frame of Projects applied under No. TR 34014 and No. ON 174009.

\section{REFERENCES}

[1] Aissaoui, N., Haouari, M., \& Hassini, E. (2007). Supplier selection and order lot sizing modelling: A review. Computers and Operations Research, 34(12), 3516-3540. https://doi.org/10.1016/j.cor.2006.01.016

[2] Moreno, J. R., Mula, J., \& Campuzano-Bolarin, F. (2015). Increasing the Equity of a Flower Supply Chain by Improving Order Management and Supplier Selection. International Journal of Simulation Modelling, (14)2, 201214. https://doi.org/10.2507/IJSIMM14(2)2.284

[3] Martinec, T., Skec, S., Savsek, T., \& Perisic, M.M. (2017). Work sampling for the production development: A case study of a supplier in European automotive industry. Advances in Production Engineering \& Management, 12(4), 375-387. https://doi.org/10.14743/apem2017.4.265

[4] Boer, L. D., Labro, E., \& Morlacchi, P. (2001). A review of methods supporting supplier selection. European journal of purchasing \& supply management, 7(2), 75-89. https://doi.org/10.1016/S0969-7012(00)00028-9

[5] Gocken, M., Dosdogru, A. T., \& Boru, A. (2017). Optimization via Simulation for Inventory Control Policies and Supplier Selection. International Journal of Simulation Modelling, (16)2, 241-252. https://doi.org/10.2507/IJSIMM16(2)5.375

[6] Bai, C. \& Sarkis, J. (2010). Integrating sustainability into supplier selection with grey system and rough set methodologies. International Journal of Production Economics, 124, 252-264. https://doi.org/10.1016/j.ijpe.2009.11.023

[7] Pan, R., Zhang, W., Yang, S., \& Xiao, Y. (2014). A State Entropy Model Integrated with BSC and ANP for Supplier Evaluation and Selection. International Journal of Simulation Modelling, (13)3, 348-363. https://doi.org/10.2507/IJSIMM13(3)C013

[8] Abdolshah, M. (2013). A Review of Quality Criteria Supporting Supplier Selection. Journal of Quality and Reliability Engineering, Article ID 621073, 9 pages. https://doi.org/10.1155/2013/621073

[9] Ko, M., Tiwari, A., \& Mehnen, J. (2010). A review of soft computing applications in supply chain management. Applied Soft Computing, 10, 661-674. https://doi.org/10.1016/j.asoc.2009.09.004

[10] Mardani, A., A. Jusoh, A., \& Zavadskas, E. K. (2015). Fuzzy multiple criteria decision-making techniques and applications - Two decades review from 1994 to 2014. Expert Systems with Applications, 42(8), 4126-4148. https://doi.org/10.1016/j.eswa.2015.01.003

[11] Li, Z., Wong, W. K., \& Kwong, C. K. (2013). An Integrated Model of Material Supplier Selection and Order Allocation Using Fuzzy Extended AHP and Multiobjective Programming. Mathematical Problems in Engineering, Article ID 363718, 14 pages. https://doi.org/10.1155/2013/363718

[12] Ashlaghi, M. J. (2014). A new approach to green supplier selection based on fuzzy multi-criteria decision making method and linear physical programming. Tehnicki vjesnik, 21(3), 591-597.

[13] Bronja, H. \& Bronja, H. (2015). Two-phase selection procedure of aluminized sheet supplier by applying FAHP and fuzzy TOPSIS methodology. Tehnicki vjesnik, 22(4), 821-828. https://doi.org/10.17559/TV-20140203122653

[14] Wu, D. (2009). Supplier selection: a hybrid model using DEA, decision tree and neural network. Expert Systems with Applications, 36, 9105-9112. https://doi.org/10.1016/j.eswa.2008.12.039

[15] Vahdani, B., Iranmanesh, S. H., Meysam, S., Mousavi, M., \& Abdollahzade, M. (2012). A locally linear neuro-fuzzy model for supplier selection in cosmetics industry. Applied Mathematical Modelling, 36(10), 4714-4727. https://doi.org/10.1016/j.apm.2011.12.006

[16] Alavi, A. H., Gandomi, A. H., Sahab, M. G., \& Gandomi, M. (2010). Multi expression programming: a new approach to formulation of soil classification. Eng Comput., 26(2), 111118. https://doi.org/10.1007/s00366-009-0140-7

[17] Fallahpour A., Olugu, E. U., \& Musa, S. N. (2017). A hybrid model for supplier selection: integration of AHP and multi expression programming (MEP). Neural Comput \& Applic, 28, 499-504. https://doi.org/10.1007/s00521-015-2078-6

[18] Chen, C. Y., Lin, J., Lee, W., \& Chen, C. W. (2010). Fuzzy control for an oceanic structure: a case study in time-delay TLP system. J. Vib. Control, 16, 147-160. https://doi.org/10.1177/1077546309339424

[19] Chen, C. (2010). Application of fuzzy-model-based control to nonlinear structural systems with time delay: an LMI method. J. Vib. Control., 16, 1651-1672. https://doi.org/10.1177/1077546309104185

[20] Chen, C. T., Lin, C. T., \& Huang, S. F. (2006). A fuzzy approach for supplier evaluation and selection in supply chain management. International Journal of Production Economics, 102, 289-301. https://doi.org/10.1016/j.jpe.2005.03.009

[21] Oltean, M. \& Dumitrescu, D. (2002) Multi expression programming. Technical report, UBB-01-2002, BabesBolyai University, Cluj-Napoca, Romania.

[22] Gandomi H., Alavi, A. H., \& Yun, G. J. (2011). Formulation of uplift capacity of suction Caissons using multi expression programming. KSCE CivilEng., 15(2), 363-373. https://doi.org/10.1007/s12205-011-1117-9

[23] Gajovic, V., Kerkez, M., \& Kocovic, J. (2017). Modeling and simulation of logistic processes: risk assessment with a fuzzy logic technique. Simulation, 96(6), 507-518. https://doi.org/10.1177/0037549717738351

[24] Abdollahi, M., Arvan, M., \& Razmi, J. (2015). An integrated approach for supplier portfolio selection: lean or agile? Expert Systems with Applications, 42(1), 679-690. https://doi.org/10.1016/j.eswa.2014.08.019 
[25] Punniyamoorthy, M., Mathiyalagan, P., \& Parthiban, P. (2011). A strategic model using structural equation modeling and fuzzy logic in supplier selection. Expert Systems with Applications, 38(1), 458-474. https://doi.org/10.1016/j.eswa.2010.06.086

[26] Büyüközkan, G. \& Çifçi, G. (2012). Evaluation of the green supply chain management practices: a fuzzy ANP approach. Production Planning and Control, 23(6), 405-418. https://doi.org/10.1080/09537287.2011.561814

[27] Mafakheri, F., Breton, M., \& Ghoniem, A. (2011). Supplier selectionorder allocation: a two-stage multiple criteria dynamic programming approach. International Journal of Production Economics, 132(1), 52-57. https://doi.org/10.1016/j.ijpe.2011.03.005

[28] Hashemi, S. H., Karimi, A., \& Tavana, M. (2015). An integrated green supplier selection approachwith analytic network process and improved Grey relational analysis. International Journal of Production Economics, 159, 178191. https://doi.org/10.1016/j.ijpe.2014.09.027

[29] Zhu, Q., Dou, Y., \& Sarkis, J. (2010). A portfolio-based analysis for green supplier management using the analytical network process. Supply Chain Management, 15(4), 306319. https://doi.org/10.1108/13598541011054670

[30] Smith, G. N. Probability and statistics in civil engineering: an introduction, Collins, London, 1986.

[31] Wang Y- M., Luo, Y., \& Hua, Z. (2008). On the extent analysis method for fuzzy AHP and its application. European Journal of Operational Research, 186(2), 735 747. https://doi.org/10.1016/j.ejor.2007.01.050

\section{Contact information:}

Marija PAUNOVIĆ, PhD Candidate

(Corresponding author)

Department of Fundamentals Sciences

Faculty of Technical Science, University of Novi Sad,

Trg Dositeja Obradovića 6,

21000 Novi Sad, Serbia

Email: majap@rcub.bg.ac.rs

Nebojša RALEVIĆ, Full Professor

Department of Fundamentals Sciences,

Faculty of Technical Science, University of Novi Sad

Trg Dositeja Obradovića 6 ,

21000 Novi Sad, Serbia

E-mail: nralevic@uns.ac.rs

Olivera MILUTINOVIĆ, Assistant Professor

Faculty of Law, Megatrend University,

Bulevar maršala Tolbuhina 8,

11070 Novi Beograd, Serbia

E-mail: omilutinovic@megatrend.edu.rs

Željko VOJINOVIĆ, Assistant Professor

Faculty of Economics Subotica,

University of Novi Sad,

Segedinski put 9-11,

24000 Subotica, Serbia

E-mail: zeljko.vojinovic@ef.uns.ac.rs

Biljana MLADENOVIĆ-VOJINOVIĆ, PhD Candidate

Department of Fundamentals Sciences,

Faculty of Technical Science, University of Novi Sad

Trg Dositeja Obradovića 6,

21000 Novi Sad, Serbia

Email: biljana.mv@uns.ac.rs 